\title{
SEDENTARY BEHAVIOUR PADA ANAK USIA SEKOLAH DI KECAMATAN DENPASAR TIMUR
}

\author{
Luh Mira Puspita ${ }^{1}$, Kadek Cahya Utami ${ }^{2}$ \\ ${ }^{1,2}$ Dosen Program Studi Sarjana Keperawatan dan Profesi Ners Fakultas Kedokteran Universitas Udayana \\ Jl. PB. Sudirman Denpasar, Bali, Indonesia \\ Alamat korespondensi: mirapuspita@unud.ac.id
}

\begin{abstract}
Abstrak
Obesitas pada anak berisiko tinggi menjadi obesitas dewasa dan berpotensi mengalami penyakit seperti penyakit kardiovaskular. Obesitas akan menyebabkan masalah kesehatan pada anak usia sekolah yaitu sekitar 20-30\% anak menderita hipertensi, diabetes meillitus tipe 2 dan sleep apnea. Anak juga akan mengalami gangguan psikososial seperti depresi dan rasa percaya diri yang rendah. Salah satu faktor penyebab obesitas pada anak usia sekolah yaitu sedentary behaviour terdiri dari membaca, duduk, dan screen based activity (menonton televisi, bermain video game, bermain komputer dan bermain smartphone). Hasil riset di Bali khususnya di Kota Denpasar, anak usia lebih dari sepuluh tahun yang melakukan sedentary behaviour terbanyak yaitu selama 6 jam per harinya dan hasilnya sebesar 44,0\%. Penelitian ini bertujuan untuk mengidentifikasi sedentary behaviour pada anak usia sekolah di Kecamatan Denpasar Timur. Jenis penelitian ini adalah penelitian deskriptif dengan desain penelitian menggunakan studi kohort. Sampel dalam penelitian ini adalah anak sekolah dasar usia 10-12 tahun yang berjumlah 122 anak. Hasil yang diperoleh bahwa sedentary behavior yang paling banyak dilakukan oleh anak usia sekolah adalah screen based activity khususnya menonton televisi. Orangtua disarankan untuk membatasi aktivitas menonton televisi pada anak dan meningkatkan aktivitas fisik.
\end{abstract}

Kata kunci: anak usia sekolah, screen based activity, sedentary behavior

\begin{abstract}
Obese children are at high risk of becoming obese as adults and have the potential to experience diseases such as cardiovascular disease. Obesity will cause health problems in school-age children, which is around $20-30 \%$ of children suffer from hypertension, type 2 diabetes meillitus and sleep apnea. Children will also experience psychosocial disorders such as depression and low self-esteem. One of the causes of obesity in school-age children is sedentary behavior consisting of reading, sitting, and screen-based activity (watching television, playing video games, playing computers and playing smartphones). The results of research in Bali, especially in the city of Denpasar, children above ten years who do the most sedentary behavior is for 6 hours per day and the result is $44.0 \%$. This study aimed to identify sedentary behavior in school age children. This type of research is deskriptive research and used a cohort study. Sample in this study were 122 elementary school children aged 10-12 years. The results obtained that the most sedentary behavior is often carried out by school-age children is screen-based activity especially watching television. Parents are advised to limit the activity of watching television to children and increasing physical activity.
\end{abstract}

Keyword: school-age children, screen based activity, sedentary behavior

\section{PENDAHULUAN}

Obesitas atau kelebihan berat badan dari segi kesehatan merupakan salah satu penyakit akibat asupan gizi yang jauh melebihi kebutuhannya. Prevalensi secara nasional mengenai masalah kegemukan pada anak usia 612 tahun masih dikategorikan tinggi. Menurut hasil dari Riset Kesehatan Dasar (Riskesdas) tahun 2013 yaitu sebesar $18,8 \%$ yang terdiri dari gemuk
$10,8 \%$ dan sangat gemuk (obesitas) $8,0 \%$. Bali termasuk dalam urutan 15 besar provinsi dengan obesitas pada anak usia 6-12 tahun terbanyak di Indonesia. Prevalensi obesitas di Bali dilihat dari Indeks Masa Tubuh (IMT) pada anak usia 6-12 tahun dari sembilan kabupaten atau kota yang ada sebanyak 8,8\%. Kota Denpasar merupakan kota dengan jumlah gizi lebih dan obesitas pada anak usia 6-12 
tahun cukup tinggi di Bali. Jumlah anak dengan gizi lebih yaitu sebanyak 762 orang dan jumlah obesitas yaitu 342 orang dari 14.017 orang anak usia 6-12 tahun di kota Denpasar. Menurut data yang didapatkan dari 225 sekolah di kota Denpasar, 25 sekolah yang berada di wilayah Puskesmas II Denpasar Timur merupakan anak usia sekolah dengan gizi lebih dan obesitas tertinggi yaitu sejumlah 189 orang dengan gizi lebih dan 87 orang dengan obesitas (Dinas Kesehatan Kota Denpasar, 2016).

Obesitas pada anak berisiko tinggi menjadi obesitas dewasa dan berpotensi mengalami penyakit seperti penyakit kardiovaskular. Obesitas akan menyebabkan masalah kesehatan pada anak usia sekolah yaitu sekitar 20-30\% anak menderita hipertensi, diabetes meillitus tipe 2 dan sleep apnea (Centers for Disease Control and Prevention (CDC), 2016). Anak juga akan mengalami gangguan psikososial seperti depresi dan rasa percaya diri yang rendah (American Academy of Pediatrics, 2015).

Faktor yang paling mempengaruhi status gizi adalah asupan makanan dan aktivitas seharihari. Beberapa studi juga menyatakan bahwa faktor personal, tingkah laku, dan lingkungan memiliki peran yang penting terhadap kebiasaan makan dan aktivitas pada anak. Anak berpotensi mengalami gizi lebih dan obesitas karena kurangnya aktivitas fisik (Larouche, 2014). Salah satu faktor penyebab obesitas pada anak usia sekolah yaitu sedentary behaviour terdiri dari membaca, duduk, dan screen based activity (menonton televisi, bermain video game, bermain komputer dan bermain smartphone) (Owen, 2010).
Menurut hasil dari Riskesdas (2013) menunjukkan hampir separuh proporsi penduduk yang melakukan sedentary behaviour selama 3-5,9 jam per harinya adalah anak usia lebih dari sepuluh tahun yaitu sebesar $42,0 \%$. Anak laki-laki dan perempuan lebih banyak melakukan sedentary behaviour selama 3-5,9 jam per harinya. Berdasarkan jenis kelamin, anak laki-laki dan perempuan yang melakukan sedentary behaviour yaitu selama <3 jam per harinya yaitu anak laki-laki sebesar $34,7 \%$ dan anak perempuan sebesar $33,0 \%$, selama 35,9 jam per harinya yaitu anak lakilaki sebesar 43,1\% dan anak perempuan sebesar $40,9 \%$ dan selama $>6$ jam per harinya anak laki-laki yaitu sebesar 22,2\% dan anak perempuan sebesar 26,1\%. Hasil riset di Bali khususnya di Kota Denpasar, anak usia lebih dari sepuluh tahun yang melakukan sedentary behaviour terbanyak yaitu selama 6 jam per harinya dan hasilnya sebesar 44,0\%. Hal ini menunjukkan bahwa anak usia sekolah lebih banyak menghabiskan separuh waktunya untuk melakukan sedentary behaviour.

Penelitian ini bertujuan untuk menganalisis sedentary behaviour pada anak usia sekolah di Kota Denpasar.

\section{METODE PENELITIAN}

Penelitian ini merupakan penelitian deskriptif dengan pendekatan kohort. Tempat penelitian adalah wilayah kerja Puskesmas II Denpasar Timur. Sekolah dasar yang terpilih menjadi tempat penelitian adalah SD 5 Kesiman dan SD 3 Penatih. Penelitian dilaksanakan pada bulan September-Oktober 2018. 
Populasi dalam penelitian ini adalah anak usia sekolah yang berada di wilayah kerja Puskesmas II Denpasar Timur. Teknik pengambilan sampel dilakukan dengan cara probability sampling yaitu simple random sampling untuk sekolah dasar yang dijadikan tempat penelitian. Sedangkan penentuan individu (anak) yang menjadi sampel ditentukan dengan teknik sampling jenuh yaitu semua anak yang berusia diatas 10 tahun sebagai sampel penelitian.

Penelitian ini menggunakan Adolescent Sedentary Activity Questionnare (ASAQ) yang merupakan salah satu kuesioner untuk mengetahui berapa jam atau berapa menit anak usia sekolah menghabiskan waktu untuk melakukan aktivitas sedentari. Kuesioner ASAQ ini diukur selama satu minggu yaitu hari sekolah (senin, selasa, rabu, kamis dan jumat) dan hari libur (hari sabtu- minggu). Kuesioner ini ditujukan untuk anak usia 11 tahun sampai usia 18 tahun. Aktivitas sedentary ini diukur selama seminggu yaitu hari senin sampai sabtu (hari sekolah) dan hari minggu (hari libur).

Analisis dilakukan dengan mengakumulasi jumlah jam untuk masing-masing kegiatan yang dilakukan oleh responden pada hari sekolah (senin-jumat) dan pada hari libur (sabtu-minggu). Sedentary behaviour dikategorikan tinggi jika dilakukan lebih dari 2 jam perhari untuk setiap kegiatan.

\section{HASIL PENELITIAN}

Berikut ini merupakan hasil sedentary behaviour pada 155 orang

siswa SD 5 Kesiman dan SD 3 Penatih yang menjadi responden

Tabel 1. Sedentary Behaviour pada Anak Usia Sekolah di Kecamatan Denpasar Timur (n=122)

\begin{tabular}{|c|c|c|c|c|c|}
\hline \multirow{2}{*}{\multicolumn{2}{|c|}{ Aktivitas }} & \multicolumn{2}{|c|}{ Weekday } & \multicolumn{2}{|c|}{ Weekend } \\
\hline & & \multirow{2}{*}{$\begin{array}{l}\text { Mean } \\
0.36\end{array}$} & SD & Mean & SD \\
\hline & ing & & 0.44 & 0.48 & 0.70 \\
\hline \multicolumn{6}{|c|}{ Sitting } \\
\hline- & Do homework & 0.79 & 0.48 & 0.70 & 0.73 \\
\hline- & Ride on car or motorcycle & 0.67 & 1.10 & 0.65 & 1.23 \\
\hline- & Take lesson & 0.46 & 0.53 & 0.33 & 0.62 \\
\hline \multicolumn{6}{|c|}{ Screen based activity } \\
\hline- & Watching TV & 1.66 & 1.09 & 2.03 & 2.04 \\
\hline- & Watching DVD & 0.09 & 0.23 & 0.06 & 0.18 \\
\hline- & Using Computer & 0.13 & 0.52 & 0.05 & 0.22 \\
\hline- & Using Hp & 0.79 & 0.68 & 0.87 & 0.91 \\
\hline- & Playing Video Games & 0.19 & 0.48 & 0.15 & 0.43 \\
\hline
\end{tabular}

Berdasarkan Tabel 1, sedentary behavior yang paling banyak dilakukan oleh anak sekolah dasar adalah screen based activity khususnya menonton TV.
Rata-rata anak sekolah dasar menonton TV pada hari sekolah sebanyak 1.66 jam/hari dan pada hari libur sebanyak 2.03 jam/hari. Kegiatan menonton TV 
pada anak usia sekolah dikategorikan tinggi karena lebih dari 2 jam/hari.

\section{PEMBAHASAN}

Sedentary behavior adalah berbagai perilaku dengan karakteristik penggunaan energi yang rendah atau kurang dari 1.5 metabolic equivalents (METs) termasuk aktivitas duduk dan berbaring. Secara umum, semua aktivitas yang menggunakan posisi duduk dan berbaring dianggap sedentary behavior. Sedentary behavior yang biasa dilakukan adalah membaca, duduk (berkendara, mengerjakan PR, mengikuti les), dan screen based activity (menonton televisi, bermain game elektornik, bermain handphone).

Hasil penelitian menunjukkan sedentary behaviour yang dilakukan anak usia sekolah paling sering adalah screen based activity khususnya menoton TV. Pada hari sekolah rata-rata anak menonton TV lebih dari 1 jam perhari dan meningkat pada saat hari libur yaitu lebih dari 2 jam perhari. Kegiatan lain yang juga meningkat frekuensinya saat hari libur membaca dan menggunakan HP. Hasil penelitian ini sesuai dengan penelitian sebelumnya bahwa sedentary behaviour paling sering dilakukan saat hari libur dibandingkan hari sekolah (Salmon, Tremblay, Marshall, \& Hume, 2011). Namun kegiatan duduk (mengerjakan PR, berkendara, dan mengikui les) serta kegiatan menggunakan komputer, cenderung menurun saat hari libur.

Sedentary behaviour yang tinggi dapat disebabkan karena faktor usia. Aktivitas terbanyak pada anak usia sekolah adalah menonton televisi dan bermain games (Hoyos \& Jago, 2010). Faktor ini diperkuat dengan hasil penelitian yang dilakukan oleh Lee, et al., (2015) yaitu anak usia 7-12 tahun rata-rata menghabiskan waktu selama 3,1 jam per harinya untuk melakukan aktivitas menonton televisi, bermain komputer dan bermain video games. Berdasarkan faktor lokasi, Denpasar merupakan daerah perkotaan. sedentary behaviour yang paling banyak dilakukan ternyata adalah anak yang tinggal di daerah perkotaan dibandingkan daerah perdesaan (Hardy, et al., 2010). Hal ini didukung dari penelitian yang dilakukan oleh Lee, et al. (2015) bahwa anak yang tinggal di kota paling banyak melakukan sedentary behaviour selama lebih dari dua jam karena anak yang tinggal di desa masih aktif melakukan aktivitas fisik di lingkungan luar.

Kemudahan mengakses alatalat elektronik juga dapat mendukung sedentary behaviour yang dilakukan anak usia sekolah (Hale \& Guan, 2015). Penggunaan TV ada anak usia 9-15 tahun di Indonesia mencapai 88,8\% (KEMKOMINFO RI, 2015). Hasil penelitian oleh Fletcher, Whitaker, Marino, dan Anderson (2014) bahwa keberadaan televisi di dalam kamar memicu anak menghabiskan waktunya untuk menonton televisi. Anak yang memiliki televisi di dalam kamarnya cenderung selalu berada di depan layar televisi dan malas untuk melakukan aktivitas lainnya (Sijtsma, Koller, Sauer, dan Corpeiljn, 2015). Pengguna telepon genggam pada anak usia 9-15 tahun di Indonesia juga tinggi yaitu $62,8 \%$ dan paling banyak digunakan untuk media sosial (ITU, 2016).

Faktor lainnya yang menyebabkan anak aktif melakukan sedentary behaviour adalah perilaku orang tua yang membebaskan anaknya untuk melakukan sedentary behaviour dan menganggap aktivitas itu penting (Hoyos \& Jago, 2010). Orangtua 
menganggap penting untuk anak melakukan sedentary behaviour seperti bermain game online dan menonton youtube bersama teman (Jago, Salomon-Moore, Toumpakari, Lawlor, Thompson, dan Sebire, 2018). Perilaku orangtua ini dapat meningkatan sedentary behaviour sebanyak $20 \%$ pada laki-laki dan $23 \%$ pada perempuan yang menyebabkan anak ketergantungan terhadap alat-alat elektronik yang disediakan.

Faktor yang juga dapat mendukung peningkatan sedentary behaviour adalah norma atau aturan yang mengharuskan anak-anak untuk duduk. Orangtua sering memerintahkan anaknya untuk duduk selama aktivitas secara tidak langsung meningkatkan sedentary behaviour (Atkin, Corder, Ekelund, Wijndaele, Griffin, van Sluijs, 2013). Lingkungan sekolah yang didesain untuk tidak berpindah-pindah saat melakukan kegiatan juga mempengaruhi terjadinya sedentary behaviour. Anak-anak akan lebih aktif secara fisik jika lingkungan kelas dibuat sesuai untuk berperilaku aktif, misalnya dengan menyediakan papan tulis yang bisa berpindah sehingga proses belajar akan lebih aktif. Kegiatan duduk yang dianggap sebagai suatu kebiasaan juga dapat memicu sendentary behaviour. Anak-anak melakukan berbagai kegiatan dengan posisi duduk karena

\section{DAFTAR PUSTAKA}

American Academy of Pediatrics. (2015). Screening and interventions for overweight in children and adolescents. Pediatrics, 116(1), 205-9.

http://pediatrics.aappublications.org /content/pediatrics/116/1/205.full.p df melihat orangtua dan orang disekitarnya melakukan hal tersebut. Perilaku ini menyebabkan sedentary behaviour menjadi suatu kebiasaan yang dianggap wajar (Hidding, Altenburg, Ekris, and Chinapaw, 2017)

Intervensi yang dapat dilakukan untuk mengurangi sedentary behaviour salah satunya adalah dengan memberikan promosi kesehatan di lingkungan sekolah. Promosi kesehatan yang dapat diberikan berupa peningkatan aktivitas fisik dan memperbaiki perilaku makan. Dukungan orangtua, modifikasi lingkungan, serta kebijakan khusus terkait aktivitas disekolah juga diperlukan untuk mendukung pengurangan sedentary behaviour yang dilakukan anak usia sekolah (Minges et al., 2016)

\section{KESIMPULAN DAN SARAN}

Kesimpulan dari penelitian ini adalah screen based activity khususnya menonton TV merupakan sedentary behaviour yang paling banyak dilakukan oleh anak usia sekolah dasar. Orangtua diharapkan membatasi sedentary behavior anak dengan meningkatkan aktivitas fisik yang memerlukan energi yang banyak namun tetap memperhatikan asupan nutrisi anak .

Atkin A.J., Corder K., Ekelund U., Wijndaele K., Griffin S.J., van Sluijs E.M.F. (2013). Determinants of change in children's sedentary time. PLOS ONE. doi: 10.1371/journal.pone.0067627.

Centers For Disease Control And Prevention. (2016). Childhood Obesity Causes 
\& Consequence. (Online Diakses Melalui Https://Www.Cdc.Gov/Ob esity/Childhood/Causes.Ht ml Pada Tanggal 9 Januari 2018)

Dinas Kesehatan Kota Denpasar. (2016). Rekapitulasi Hasil Penjaringan Kesehatan Peserta Didik Di Wilayah Kerja Seluruh Puskesmas Kota Denpasar. Denpasar.

Fletcher, E. N., Whitaker, R. C., Marino, A. J. \& Anderson, S. E. (2014). Screen time at home and school among low-income children attending head start. Child Indicators Research, 7(2), 421-436. doi: $\underline{10.1007 / \mathrm{s} 12187-013-9212-}$ 8

Hale, L., \& Guan, S. (2015). Screen time and sleep among school-aged children and adolescents: A systematic literature review. Sleep Medicine Reviews, 21, 5058.

doi: $\quad \underline{10.1016 / j . s m r v .2014 . ~}$ $\underline{07.007}$

Hardy, L., King, L., Espinel, P., Cosgrove, C., \& Bauman, A. (2010). NSW schools physical activity and nutrition survey (spans)-full report. N. M. o. health. Sydney: NSW Ministry of Health.

Hoyos, C. I. \& Jago, R. (2010). Systematic review of correlates of screen-viewing among young children. Preventive Medicine, 51(1), 3-10.

doi: 10.1016/j.ypmed.2010.04.0 12

Hidding L M., Altenburg T M., Ekris E V., and Chinapaw M J M. (2017) Why Do Children Engage in Sedentary Behavior? Child- and Parent-Perceived Determinants. Int. J. Environ. Res. Public Health 14 , 671 ; doi:10.3390/ijerph1407067

International Telecommunication Union (ITU). (2016). Country ICT data: Mobilecellular subscription. Diakses melalui https://www.itu.int/en/ITUD/Statistics/Pages/stat/defa ult.aspx

Jago, R., Salomon-Moore, E., Toumpakari, Z., Lawlor, D. A., Thompson, J. L., \& Sebire, S. J. (2018). Parents perspective of change in child physical activity \& screen-viewing between $\mathrm{Y} 1$ (5-6) \& Y4 (8-9) of primary school: Implications for behavior change. $B M C$ Public Health 18, 520. https://doi.org/10.1186/s12 889-018-5445-2

Jong E D., Visscher T L., HiraSing R A., Heymans M W., Seidell J C., \& Renders C M. (2013). Association between TV viewing, computer use and overweight, determinants and competing activities of screen time in 4- to 13-yearold children. International Journal of Obesity, 37, 4753 
Kementrian Komunikasi dan Informatika Republik Indonesia. (2015). Peta industri game di Indonesia. Direktorat Pemberdayaan Informatika Kementrian Komunikasi dan Informatika.

Larouche, R. (2014). Assessing the health-related outcomes and correlates of active transportation in children and youth. Applied Physiology, Nutrition \& Metabolism, 39, 403-403. http://www.nrcresearchpres s.com/doi/pdf/10.1139/apn m-2013-0450

Lee, S. T., Wong, J. E., Shanita, S. N., Ismail, M. N., Deurenberg, P. \& Poh, B.K. (2015). Daily physical activity and screen time, but not other sedentary activities, are associated with measures of obesity during childhood. International Journal of Environmental Research and Public Health, 12, 146161.

Minges K E., Chao A M., rwin M L., Owen N., Park C.,
Whittemore R., Salmon J. (2016). Classroom Standing Desks and Sedentary Behavior: A Systematic Review. PEDIATRICS Volume 137, number 2

Riset Kesehatan Dasar. (2013). Laporan Hasil Riset Kesehatan Dasar Indonesia. Jakarta: Kementrian Kesehatan R.I.

Salmon J., Tremblay M. S., Marshall, S. J. \& Hume, C. (2011). Health risks, correlates and interventions to reduce sedentary behavior in young people. American Journal of Preventive Medicine, 41(2), 197-206. doi: 10.1016/j.amepre.2011.05. 001

Sijtsma, A., Koller, M. Sauer, P. J. J \& Corpeiljn, E. (2015). Television, Sleep, Outdoor Play Bmi In Young Children: The Gecko Drenthe Cohort. European Journal of Pediatric, 174(5), 631-9. Doi: $\quad 10.1007 /$ S00431014-2443-Y 